\title{
A PSICODINÂMICA CONJUGAL E A CONTEMPORANEIDADE
}

\author{
Anamaria Silva Neves* \\ Andrezza Sisconeto Ferreira Dias** \\ João Luiz Leitão Paravidini***
}

\section{Resumo}

Este artigo pretende discutir a conjugalidade em interface com aspectos contemporâneos como a valorização do individualismo e a cultura narcísica e hedonista, em que a exaltação da felicidade é extremamente valorizada e há um apelo ao não sofrimento. Atualmente tal concepção é enfatizada com a crença de que uma relaçáo conjugal deve ser mantida apenas se propiciar prazer e bem-estar. Por outro lado, encontram-se casais que permanecem juntos, mesmo quando esse ideal não se realiza, e que vivem relações marcadas pelo conflito, sofrimento e muitas vezes violência conjugal. Esse pode ser um dos pontos de desdobramento para responder aos ideais da atualidade. Através da apresentação de um fragmento de caso clínico de um atendimento individual de orientação psicanalítica, mas que tem a conjugalidade como questão central, discutem-se os impasses vivenciados por um casal e sua inter-relação com os ideais contemporâneos e a dinâmica conjugal. Conclui-se que os casais sofrem influência desses ideais, mas que os elementos da psicodinâmica do casal devem ser concomitantemente analisados para melhor entendimento do universo conjugal. Acredita-se que a psicanálise seja um instrumento importante nesse sentido por considerar aspectos inconscientes na trama conjugal e a singularidade de cada história construída pelo casal.

Palavras-chave: conjugalidade; contemporaneidade; psicodinâmica conjugal.

* Universidade Federal de Uberlândia, Uberlândia, MG, Brasil.

** Universidade Federal de Uberlândia, Uberlândia, MG, Brasil.

*** Universidade Federal de Uberlândia, Uberlândia, MG, Brasil. 


\begin{abstract}
THE MARITAL PSYCHODYNAMICS AND THE CONTEMPORARY

This article discusses the conjugal interface with contemporary issues as the value of individualism and narcissistic and hedonistic culture, in with the exaltation of happiness is extremely valuable and there is a call no suffering. Currently this concept is emphasized with the belief that a relationship should be maintained only provide pleasure and well-being. On the other hand, there are couples, who stay together, even when this ideal is achieved, and living relations marked by conflict, suffering and domestic violence. This may be one deployment to respond to the ideals of today. Through the presentation of a clinical fragment of an individual therapy, but that has conjugality as a central issue is discussed the impasse experienced by a couple and their interrelation with contemporary ideas and marital dynamics. The conclusion is that couples are influenced by contemporary ideals, but that elements of psychodynamics of the couple must be simultaneously analyzed to better understand the universe marriage. It is believed that psychoanalysis is an important tool in this sense, considering the plot unconscious aspects of marriage and uniquesses of each story built by couple.
\end{abstract}

Keywords: marital; contemporary; marital psychodynamics.

\title{
Resumen
}

\section{LA PSICODINÁMICA CONYUGAL Y CONTEMPORANEIDAD}

Este artículo aborda la interfaz conyugal con aspectos contemporáneos como la valoración del individualismo y la cultura narcisista y hedonista, en la que la exaltación de la felicidad es muy valorada y hay un llamado a no sufrir. En la actualidad este concepto se acentúa con la creencia de que una relación matrimonial debe mantenerse sólo de proporcionar placer y bienestar. Por otro lado, están las parejas permanecen juntas, aun cuando este ideal no se lleva a cabo, y las relaciones en directo marcadas por el sufrimiento de conflictos y con frecuencia la violencia doméstica. Esta puede ser una de la implementación para cumplir con los ideales de hoy. A través de la presentación de un fragmento de un caso de una psicoterapia de atención individual, pero que tiene el problema central conyugal discute los dilemas experimentados por una pareja y su interrelación con los ideales contemporáneos y dinámicas conyugales. Llegamos a la conclusión de que las parejas sufren la influencia de estos ideales, pero que los elementos de la pareja psicodinámica deberán ser analizadas simultáneamente para una mejor comprensión del universo conyugal. Se cree que el psicoanálisis es una herramienta impor- 
tante en este sentido, teniendo en cuenta los aspectos inconscientes de la trama y la singularidad de cada historia civil construido por la pareja.

Palabras clave: conyugal; contemporaneidad; psicodinámica conyugal.

\section{Introduçáo}

O que realmente tem mudado a conjugalidade na contemporaneidade? Podemos encontrar na sociedade pós-moderna sujeitos que desejam construir um vínculo conjugal duradouro e estável? Como os casais lidam com a perspectiva social que dita a obrigatoriedade da felicidade e da realização individual? Tais questóes conduzem o caminho do texto a seguir.

Um dos conflitos centrais da atualidade envolve a ânsia de homens e mulheres pelo estabelecimento de laços que lhes confiram algum sentimento de pertencimento e segurança, mas, ao mesmo tempo, é notório que ambos, homens e mulheres, desconfiam da condição de permanecerem juntos, sobretudo permanentemente, pois não sabem se estão dispostos ou se conseguirão enfrentar os dissabores e tensôes de uma vida em comum e, ainda, se estão disponíveis para abrir mão da liberdade individual, tão valorizada e prezada na contemporaneidade. Tais conjecturas partem de Bauman (2004). Em sua obra Amor líquido, o autor enfatiza a fragilidade dos laços humanos e o quanto esta tem provocado insegurança e criado conflitos no sentido de os sujeitos permanecerem divididos entre "apertar" tais laços ou "afrouxá-los".

Nesse sentido, ficar só ou unir-se a alguém, constituindo um vínculo mais duradouro e estável, parece ter se tornado um dilema na vida dos sujeitos, visto que se vivencia uma cultura marcada pelo individualismo e exaltação das conquistas pessoais, entre elas o sucesso profissional e a realização pessoal. Para isso, há um movimento de engajamento em si mesmo, nos próprios projetos e um adiamento da conjugalidade, ou mesmo um questionamento se esta deve ser ou náo vivenciada. Uma vez constituída, os dilemas contemporâneos do individualismo versus conjugalidade passam a permear os casais contemporâneos. Acredita-se que não sem conflito tais situaçóes sejam vivenciadas pelos sujeitos e pelos casais.

Para Féres-Carneiro e Ziviani (2009), um dos desafios contemporâneos para o casal é articular individualidade e conjugalidade. Uma vez postas a valorização da liberdade e as conquistas dela decorrentes, considera-se que conflitos e impasses poderão advir de uma relaçáo em que cada sujeito do casal voltar-se-ia para si mesmo, priorizando sobressair em uma sociedade marcadamente individualista. 
A respeito do individualismo exacerbado, Lasch (1998), fazendo referência ao momento atual, expóe a cultura do narcisismo, que é expressa pelos desejos sem limites e anulaçóes do outro, na qual o centro é o próprio eu. $\mathrm{O}$ apelo social convida os sujeitos a serem sempre mais, terem sempre mais... Mais sucesso, trabalho, capacitação, dinheiro, amor, felicidade; enfim, a lista de exigências a serem cumpridas é enorme. E os impasses decorrentes de todas essas "prescriçôes" parecem afetar consideravelmente não apenas os indivíduos solteiros, mas também os casais.

\section{“Bem me quer, mal me quer”...}

Como apontado, permanecer sozinho ou constituir uma conjugalidade se apresenta como um paradoxo no momento atual, pois, ao mesmo tempo que o individualismo é tão valorizado, o ideal do amor e da felicidade e a conjunção de ambos continuam a ser almejados. Tais ideais não dizem respeito apenas ao momento específico em que se vive, podem-se encontrar referências nesse sentido em outros períodos da sociedade ocidental.

Freud (1930/1980), em "O mal-estar na civilizaçáo", descreve a busca pelo amor não apenas como um caminho para se atingir a felicidade, pois reconhece nesse sentimento um dos elementos fundantes da civilizaçáo. Ao perceber que suas necessidades eróticas apresentavam-se permanentemente, o homem uniu-se a uma mulher e formou uma família. No entanto, na busca de um objeto externo para a realização do amor genital, corre-se o risco de perdê-lo e tal possibilidade expóe o homem a um grande sofrimento. Freud destaca, inclusive, que os relacionamentos humanos são uma das três principais fontes de sofrimento, aqueles que mais são capazes de gerar dor e lançar o homem no desamparo. Mesmo assim, no projeto de estado de felicidade permanente e evitaçáo do sofrimento, o amor parece nunca ter sido deixado como possibilidade da táo aclamada felicidade.

Autores contemporâneos que tratam do tema da felicidade e do amor apresentam aproximaçóes ao pensamento freudiano. $\mathrm{Na}$ obra Os tempos hipermodernos, Lipovetsky (2004) afirma que, embora as relaçóes possam estar mais fragilizadas, ainda há na contemporaneidade uma persistência no casamento, assim como a valorização da fidelidade e o desejo de manutenção de relaçóes estáveis na vida amorosa. Depreende-se de tais argumentaçóes que é ao desejo por relaçóes duradouras que o autor faz referência, não necessariamente ao casamento nos moldes tradicionais (civil e religioso). Contudo, uma ressalva pode ser feita nesse sentido, pois na atualidade muitos casamentos são verdadeiros empreendimentos: todo 
um espetáculo é criado em torno do evento, que pode representar a introjeção dos valores contemporâneos relacionados à grandiosidade e à suntuosidade bem como a elevadas expectativas com relação à conjugalidade.

Lipovetsky (1983) afirma ainda que na pós-modernidade fica diminuída a preocupação com a hierarquia das relaçóes, que estão mais verticalizadas, tendo como consequência a multiplicidade de possibilidades, opçóes e ideais. No que diz respeito à conjugalidade, observa-se o fenômeno nos múltiplos arranjos conjugais, nas diversas formas de se vivenciar um relacionamento. Pode-se, na atualidade, falar em famílias recompostas, homoafetivas, monoparentais, ou seja, dadas as novas configuraçóes conjugais e familiares, o que está em questão aqui é a formação da conjugalidade, o quanto esta ainda é desejada e pode ser vivenciada sob diversos formatos.

Jablonski (2007) corrobora tal discussão. Em uma pesquisa sobre expectativas dos sujeitos acerca das mudanças na concepçáo ideal de casamento e composição familiar (principalmente devido ao movimento feminista e suas repercussóes), o autor concluiu que os jovens entrevistados permanecem dispostos a se casar. Presume-se, assim, que a vivência da relação amorosa, do estreitamento de vínculos e da conjugalidade é ainda um ideal pós-moderno, ou seja, os sujeitos continuam a buscar no outro o amor e o sentimento de felicidade.

Amor e felicidade são temas significativos retratados nas artes em geral e em algumas ciências sob diferentes enfoques e abordagens. A psicanálise também se ocupa desse assunto. Conflito, sofrimento e dificuldades conjugais adentram os consultórios com sujeitos que apresentam seus dramas e histórias nos relatos individuais ou grupais, dentre estes os casais.

\section{O amor na psicanálise}

Para a psicanálise, a busca pelo amor pode ser entendida como uma ilusão de que se encontre na realidade o objeto perdido e com ele a satisfação já experimentada. Assim, ao reconhecer no outro algum traço representativo do objeto perdido, o sujeito lança-se em um movimento pulsional em sua direção, com vistas a realizar o desejo de complementaridade. Tal fenômeno é assim descrito por Alvarenga (1996), que apresenta uma leitura psicanalítica do laço conjugal.

Destaca-se um elemento conceitual fundamental: a ilusão. Ilusão que para a psicanálise é fundante do vínculo amoroso: entendida não como algo falso, mas como algo que é "um produto dos desejos humanos" (Zago, 2009, p. 119). Na ilusão, o outro pode ser quem se deseja; portanto, no apaixonamento, o outro 
pode se tornar facilmente fonte de gratificação, dotado de características únicas, exclusivas e especiais, inclusive se tornando alguém que complementa o que falta ao outro. O caráter de complementaridade que foi aqui destacado toma forma nesse processo, pois na condiçâa faltante o outro se torna essencial para "preencher" essa falta.

Alvarenga (1996) destaca que, ao se retomar as primeiras experiências do bebê, observa-se uma condição em que a libido não era diferenciada, mãe e bebê viviam em um estado de fusão em que o pequeno ser não fazia a distinção entre o eu e o não-eu. Com o decorrer das experiências de frustração vivenciadas pelo bebê, a ilusão de completude se desfaz e o sujeito gradualmente se afasta desse estado de narcisismo primário. Esse é um percurso necessário ao desenvolvimento do eu, para o qual o sujeito busca retornar, sendo esta uma operação inter-relacionada com a escolha amorosa.

Essa condição de falta é interessante para se pensar o vínculo amoroso, uma vez que na atualidade vive-se a cultura narcísica, que culmina com o autocentramento, com as prerrogativas das facilidades de uma vida individualista, características do público alvo de todo um mercado voltado para a execução de produtos e serviços prontos a atendê-lo, desde as porçóes individuais nos supermercados até as viagens programadas para solteiros. Entretanto, a mesma condição faltante parece impelir o sujeito a um movimento pulsional, como bem descreve Alvarenga (1996), a fim de reencontrar o objeto perdido. Apreende-se que de forma ambivalente, na condição da falta humana, a busca pelo outro é própria da pulsão, mas ao mesmo tempo há o individualismo colocado pela pós-modernidade, e tal ambivalência é vivida conflituosa e intensamente pelos sujeitos.

Gomes e Porchat (2006, p. 137) argumentam que a busca pelo vínculo, pelo outro, é uma "força motriz básica do ser humano", podendo a relação conjugal ser fonte de preenchimento, amadurecimento e realização. Pode ser entendida como força que impele os sujeitos a uma busca amorosa e que permanece presente na contemporaneidade; no entanto, com as particularidades do momento em que se vive, o individualismo e o hedonismo contemporâneo tomam a cena.

\section{Amor, desamparo e felicidade}

A noção de falta remete à vivência humana do desamparo, fenômeno reconhecido na obra freudiana em vários momentos. No primeiro deles, na própria condição de prematuridade humana, a condição neotênica do bebê de dependência total do Outro para garantir a sua sobrevivência. Nesse primeiro momento, o 
que existe é uma total falta de condições físicas e psicológicas para que o pequeno ser satisfaça por si mesmo suas necessidades básicas e vitais.

Freud (1925/1980), no texto "Inibição, sintoma e ansiedade", discute que a noção de desamparo se relaciona ao trauma do nascimento e ao medo da perda do objeto de amor, do qual se é dependente. Diante dessa possibilidade, a angústia é um sinal de ameaça ao ego como uma defesa para lidar com o desamparo. $\mathrm{O}$ medo da perda do objeto de amor é algo extensivo às outras relaçóes que o indivíduo estabelece ao longo da vida.

Autores contemporâneos, como Fortes (2009), consideram que o desamparo é uma marca elementar dos tempos atuais e está relacionado às incertezas que o sujeito vive, à era do vazio, que encontra nas patologias do ato, compulsóes, drogadicções, distúrbios psicossomáticos e depressôes, sinais evidentes desse fenômeno psíquico.

Seria a conjugalidade uma das formas impetradas pelos sujeitos para lidarem com tal aspecto constituinte, já que na conjugalidade supóe-se encontrar uma vivência de plenitude, unicidade e felicidade? A exaltação da felicidade serve na atualidade como defesa para lidar com o desamparo do homem pós-moderno?

A busca da felicidade e a evitação do sofrimento são descritas por Freud em "O mal-estar da civilização" (1930/1980) como algo marcante na sociedade. Ao buscar o prazer e evitar o sofrimento, um mal-estar adviria da impossibilidade de o homem realizar seu projeto de felicidade devido às restriçóes impostas pela cultura. Ou seja, diante das exigências sociais, e pelo bem-estar da sociedade, o homem tem que renunciar às satisfaçóes pulsionais, principalmente as pulsóes agressivas e sexuais. Contudo, adverte o autor, mesmo que o programa de tornar-se feliz não possa ser realizado como o homem gostaria que fosse, não se pode abandonar a ideia de realizá-lo, de uma forma ou de outra. Nesse sentido, Freud (1930/1980) reconhece como válidos os esforços humanos para alcançar a felicidade.

A contemporaneidade é fortemente marcada por uma perspectiva hedonista, em que o ideal de felicidade é algo a ser atingido a qualquer preço; assim, "o que antes era um projeto do Id passa a ser um projeto do Superego" (Filho, 2009, p. 187), ou seja, se não é feliz, o sujeito sente-se extremamente culpado.

Não sofrer torna-se um imperativo e a evitação do sofrimento tem sido um dos ideais do homem contemporâneo em uma sociedade que cria a ilusão de que se pode ser o que se quiser, só depende do empenho individual de cada um. A contemporaneidade é marcada por uma sociedade que se regula pela imagem perfeita tanto de corpos quanto de almas. Tal aspecto pode ser claramente observado nas inúmeras técnicas de terapias que têm o objetivo de acabar com a dor humana (Marin, 2004). 
Em Fortes (2009) encontra-se leitura semelhante. A autora também afirma que hoje aquele que não consegue ser feliz é visto como uma pessoa fraca e culpada. Tal noção coloca o sujeito em uma posição extremamente vulnerável, porque a dor a ser excluída é ela mesma fonte de dor. O sujeito tem que esconder de si mesmo, de alguma forma, a dor que sente e pode-se imaginar quanto trabalho psíquico está envolvido nesse projeto, que não pode ser realizado.

Esse ideal de felicidade estende-se para a vida conjugal e parece não ser recente, embora hoje acentuado. Contudo, está presente há muito tempo no imaginário popular. Dias (2007) lembra as cantigas e ditos populares que remetem a essa questão, como a entoada "com quem será", cantada em aniversários: a valorização da cara-metade, de que algum dia se encontrará a alma gêmea e, assim, se poderá ser feliz; e o "foram felizes para sempre" dos desenhos infantis, que dizem que depois que um casal passa por determinada crise e é capaz de superá-la nada mais o destruirá.

No que tange à conjugalidade, permanece na contemporaneidade a expectativa de que o outro dê conta da condição faltante, do desamparo de cada um, de se encontrar no outro a realização e o ideal de felicidade, "laço primário, dual, que exige reciprocidade, uma troca perfeita onde um tem que saciar o outro, paranoia conjugal, que aprisiona e alimenta” (Dias, 2007, p. 24).

Também na conjugalidade a perspectiva hedonista é extremamente valorizada. Tal concepção, fortemente idealizada nos dias atuais, tem seu ideal no amor romântico, que ocorre na passagem do séc. XIX para o séc. XX, em que a satisfação sexual e emocional é extremamente valorizada. Atualmente adquire contorno mais significativo, visto que as características ressaltadas pela sociedade atual versam pela intensificação de sensaçôes prazerosas, exaltação da felicidade e do prazer, do reconhecimento narcísico e do não sofrimento. Entretanto, encontram-se muitos casais que permanecem em relaçóes marcadas pelo conflito, sofrimento e, muitas vezes, violência conjugal, cenário em que o ideal de felicidade não se concretiza ou é ameaçado constantemente por pulsóes destrutivas. Pode-se perguntar se estariam estes "isentos" da perspectiva hedonista. A psicanálise pode ajudar a problematizar e refletir sobre tais questóes.

\section{"E não foram felizes para sempre”...}

A vinheta clínica a seguir apresenta o caso de um homem atendido individualmente, mas que em sua narrativa produz, constantemente, questóes relacionadas à conjugalidade. 
Observou-se, desde o primeiro momento, que a relação conjugal estava sendo fonte de intensa angústia, acentuada com o agravamento dos conflitos entre o casal e os episódios de violência que começavam a surgir.

O casal apresentado pelo paciente em questão e inserido no contexto histórico-social vivenciava as demandas afetivas e sociais a ele correspondente. Entretanto, ele (paciente) não se encontrava no parâmetro pós-moderno de que uma relação deve ser mantida apenas se não provocar sofrimento e dor aos parceiros. Para ele a preservação do vínculo conjugal e do núcleo familiar era extremamente importante.

Antônio, 47 anos, casado há 15, com dois filhos, um adolescente e outro na pré-adolescência, procura o atendimento psicológico (de base psicanalítica) de forma espontânea, queixando-se de ansiedade, dificuldade para dormir, cansaço constante, dores generalizadas e preocupaçóes. Fica claro também na primeira entrevista que o casamento não está bom.

Trabalha na área do comércio há muitos anos, desde a adolescência. Fez um curso técnico nessa área, mas tem vontade de ir mais longe, fazer um curso superior, não só como possibilidade de ganhar melhor, mas principalmente porque sempre teve vontade de estudar em uma universidade, considera que poderia crescer muito como pessoa se tivesse essa oportunidade.

Ao mesmo tempo, e de forma ambivalente, Antônio ao longo das sessóes se apresenta como um homem simples, sem grandes ambiçóes, parece desvelar em seu discurso uma expectativa social contemporânea que dita a importância de se obter sucesso e reconhecimento. Em uma de suas falas diz: "sou um homem simples, bem mais simples que minha esposa, me satisfaço com pouca coisa, mas engraçado, parece que a gente sempre tem que estar correndo atrás de alguma coisa, se não, não está bom”. Pergunto: "Não está bom pra quem?”. E ele responde: "pra todo mundo". "Incluindo você?", pergunto. E ele responde "algumas coisas eu queria mudar, mas tudo que fiz teve importância, sempre aprendi com as experiências que tive".

Antônio é muito voltado para a família, preocupa-se bastante com o bem-estar de todos, se considera responsável por seus filhos e esposa não só financeiramente, mas também pelo bem-estar psicológico.

Desdobra-se para tentar ajustar vida financeira e conjugal. Já houve época em que, tendo dois empregos, trabalhava 14 horas por dia. Sente-se "sem saída", como ele mesmo descreve, pois "a família tem que ser mantida", mas para isso parece que Antônio tem que se anular, pois não consegue investir em si por "falta de dinheiro e tempo", ele diz.

Silencia-se diante das acusações e cobranças da esposa e da sogra, que interfere de forma significativa na relação conjugal. Sua esposa tem o tempo quase 
todo tomado pelo trabalho e acusa Antônio por trabalhar menos, pois seu horário de trabalho era menor no momento. Antônio também é cobrado pela "falta de romance" e de felicidade no casamento.

Durante as sessões, o paciente relata situações em que era humilhado e depreciado pela esposa, além das cobranças que sofria, como, por exemplo, ter que arrumar determinada quantia em dinheiro de um dia para o outro para saldar determinada dívida. A crise conjugal se acentuava e com isso os episódios de acusaçóes, cobranças, humilhações foram delineando um quadro de violência psicológica.

O impasse conjugal estava posto. Ela exigia melhora das condições de vida, associada às exigências contemporâneas. Por exemplo, o casal esforçava-se em pagar a mensalidade de um clube de lazer reconhecido na cidade, mesmo que, naquele momento, fosse algo difícil para eles, assim como em manter os filhos em uma escola considerada das melhores da cidade, entre outras exigências que eram feitas. Ele, por sua vez, considerava importante melhorar um pouco, mas considerava a simplicidade o melhor "estilo" de viver, dizendo não haver razão para só trabalhar... e trabalhar... na vida.

Tomados ambos pela expectativa contemporânea, a trama conjugal adquiria contornos específicos, culminando com o atravessamento da violência na conjugalidade. Faz-se importante considerar aqui de que violência se fala. Nessa temática, Chauí (1982), embora não se refira especificamente à violência conjugal, apresenta uma importante consideração ao afirmar que a violência impede que o sujeito se manifeste em toda a sua singularidade, impondo à subjetividade restrição, ordem, opressão e impossibilidade de ser através da manifestação acentuada da negaçáo do outro.

Tal descrição vai de encontro à situação de violência conjugal, particularmente a violência psicológica, que é definida por Hirigoyen (2005, p. 28) como "uma série de atitudes que visa aviltar ou negar a maneira de ser de uma pessoa”, sendo esta a principal forma de violência estabelecida na conjugalidade em questão.

Antônio justificava os episódios violentos da esposa não os reconhecendo como a violência propriamente dita, mas como um momento difícil do casal, embora esse reconhecimento fosse atravessado por muito sofrimento. Por que ele ocupava tal lugar no vínculo conjugal? Gozava ele dessa posição?

Antônio encontrava-se em lugar de vítima, estava fixado nesse lugar. Sua narrativa não era uma lamentação do tipo "olha o que ela fez comigo", mas sim "ela não tem culpa, está nervosa, trabalha demais", quase dizendo: a culpa é minha. Ainda assim, trata-se de um lugar vitimizado e masoquista ao reconhecer e justificar os ataques destrutivos de sua esposa como momentâneos ou razoáveis 
devido às dificuldades que enfrentavam. Antônio dirige contra si mesmo a punição, que advém de algum sentimento de culpa, fenômeno reconhecido como masoquismo moral.

Analisando a temática do masoquismo, Fortes (2007) ressalta que:

o masoquismo moral centra-se na submissáo ao outro da moral - uma espécie de obediência irrestrita às injunçôes do outro social, o que levou Theodor Reik (1941) a denominá-lo de masoquismo social. Constitui-se de fato como um efeito do sentimento de culpa, sendo que o sofrimento aqui aparece como um destino [...] que seria alheio ao sujeito como obra do acaso (Fortes, 2007, p. 39).

O paciente achava que sempre haveria algo a fazer para corresponder às expectativas sociais de sua esposa, entre elas a de que ele conseguisse ser o provedor. Desdobrava-se para isso em atitudes como pegar dinheiro emprestado com o agiota, procurar outro trabalho a fim de complementar a renda, mesmo sabendo que o atual emprego não permitia a possibilidade de outro trabalho. Assim, punia-se e submetia-se ao desejo do outro. Claramente, Antônio se assujeitava. $\mathrm{O}$ assujeitamento está relacionado com o masoquismo feminino, proposto por Freud (1924/1974) no texto "O problema econômico do masoquismo". As condiçóes femininas, "ser castrado, ser objeto de coito ou dar à luz" (Freud, 1924/1974, p. 76), estâo intrinsecamente relacionadas às condiçôes das mulheres no início do séc. $\mathrm{XX}$, de modo que se pode inferir que tais condiçôes não são essencialmente femininas, ou seja, o assujeitamento também pode ser masculino.

Fortes (2007) ressalta que o masoquismo moral e o feminino são representativos da culpabilidade e da submissão. Antônio, ao assujeitar-se, ocupa uma posição de servidão, torna-se objeto de gozo do outro, se oferecendo como objeto de humilhaçáo. Também goza ele ao exibir seu sofrimento, afinal tenta fazer tudo certo, mas não consegue, assim não é reconhecido em seu narcisismo.

Para Alvarenga (1996),

o sujeito sempre buscará no outro o reconhecimento, sendo assim, na relação conjugal há uma expectativa de que cada parceiro reafirme a imagem que o outro tem de si mesmo [...] o movimento de buscar no outro um suporte para o seu narcisismo ou o reconhecimento de sua subjetividade esbarra em outro sujeito que, por sua vez, faz limite ao narcisismo do primeiro, ambos demandam o que o outro não tem e se confrontam com a própria castração (Alvarenga, 1996, p. 7). 
Antônio valorizava aspectos como as possibilidades de crescimento pessoal e intelectual e a simplicidade que a vida pode oferecer. Entretanto, não percebia que era também chamado a ocupar lugares na conjugalidade que envolviam tomadas de decisão, organização e demandas cotidianas que uma casa e um casal com filhos implicam. Em uma perspectiva winnicottiana (1956/2000), a violência impetrada pela esposa talvez fosse um último apelo para que ele pudesse vislumbrar uma saída menos defensiva que um lugar de vítima pode proporcionar. Por sua vez, ao não responder efetivamente aos apelos propostos por sua companheira, Antônio tentava lhe dizer que aqueles não eram seus ideais. Era importante que ambos pudessem reconhecer que um projeto de casal implica sempre em uma construção conjugal.

Bereinstein e Puget (1993), ao elaborarem parâmetros para definir o que seria um casal, incluem o que chamam de projeto vital compartilhado, que diz justamente, como o próprio nome indica, um projeto de vida em comum vivenciado pelos parceiros, o que não se relaciona com a anulação da subjetividade. Pelo contrário, é na valorização da alteridade que se pode construir algo genuíno. Pode-se dizer que a efetividade desse projeto deve ocorrer de forma dinâmica, o que implica que o casal tenha certa flexibilidade para fazer ajustes e rever o que planejou. Os autores destacam inclusive que náo se trata de o casal fazer um projeto exclusivo para a vida toda, mas, sim, de ser capaz de efetuar mudanças diante de outras possibilidades.

O casal apresentado por Antônio apresenta dificuldade nesse sentido, pois não consegue estabelecer um projeto comum. Se houvesse a possibilidade de perguntar aos mesmos "o que vocês querem como casal?", provavelmente as respostas seriam diferentes e acusatórias, na medida em que um planejava ascender a um nível socioeconômico que exige grandes esforços e dedicação e o outro desejava uma vida mais simples e modesta, sem grandes ambiçóes. O projeto vital do casal é um aspecto conflituoso.

Outra questão que pode ser observada no atendimento de Antônio é que o casal apresentava questóes relacionadas à dificuldade de se estabelecer como uma "estrutura inédita", termo também utilizado por Bereinstein e Puget (1993), que versa sobre a capacidade do casal de separar-se de sua família de origem. No casal, havia a presença não só fantasmática, mas também concreta da família de origem, que era um aspecto com o qual o casal tinha que lidar constantemente, representada principalmente pela figura da sogra de Antônio que, assim como a filha, cobrava dele mais dinheiro, mais trabalho, mais lazer, mais viagens e passeios. Havia, nesse sentido, uma interferência significativa na relação, autorizada pelo casal, contribuindo para o empobrecimento da expressão da alteridade do casal, agravando os conflitos conjugais. 


\section{Sobre nem sempre viver feliz para sempre}

O espaço para o exercício da alteridade é de significativa importância na conjugalidade. No que diz respeito às relaçôes conjugais permeadas pela violência, é comum observar-se que o espaço para a manifestação subjetiva é restrito, existindo, continuamente, a imposiçáo do desejo de um sobre o outro, náo reconhecimento da alteridade e cerceamento da liberdade de escolha.

Durante o atendimento de Antônio observou-se a dificuldade dele em lidar com tantas expectativas dirigidas a ele. Eram cobranças e imposiçóes confrontadas com sua dificuldade de negá-las, oscilando entre a negativa e viver de acordo com uma norma familiar e social instituída náo só pela dinâmica afetiva subjacente ao vínculo, mas também por uma ordem social que acomete a família e o espaço conjugal.

O casal contemporâneo é atravessado por questóes significativas relacionadas ao contexto social. Aqui foi destacado, particularmente, o conflito individualismo versus conjugalidade, pois parece que vivenciar um deles implica a anulação do outro. Como no caso de Antônio: ele se anula, pois não há como dedicar-se a si mesmo, apenas à família; mas também está imerso nas exigências sociais através do vínculo conjugal. Deseja ocupar um lugar em que tenha espaço para si mesmo, mas, como demonstrado, seus sonhos e ideais divergem dos de sua esposa, assim como dos ideais sociais.

O casal apresentado (e representado) pelo paciente vivenciava as demandas afetivas e sociais do momento contemporâneo. Para ele (paciente) a preservaçáo do vínculo conjugal e do núcleo familiar eram extremamente importantes. Segundo Levy e Gomes (2008), as exigências contemporâneas tanto para o indivíduo como para o casal são muitas, entre elas a manutenção da liberdade individual e das relaçóes conjugais justificadas apenas no prazer e na busca de perfeição. Entretanto, para as autoras, há uma ambivalência entre as expectativas sociais e o sofrimento dos casais na clínica conjugal, indicando que os elementos da psicodinâmica do casal entram em conflito com as demandas sociais, carecendo análise aprofundada.

Conclui-se das considerações teóricas apresentadas frente à complexidade da conjugalidade que os aspectos histórico-sociais são fatores significativos na dinâmica conjugal, perpassados pela constituição do vínculo, desde a escolha amorosa à construção singular da história conjugal, a trajetória percorrida pelo casal. Nesse sentido, a psicanálise torna-se ferramenta interessante para pensar a constituição da conjugalidade e a dinâmica afetiva implicada no vínculo, assim como o contexto social que enreda a conjugalidade. 


\section{Referências}

Alvarenga, L. (1996). Uma leitura psicanalítica do laço conjugal. In T. Féres-Carneiro (Ed.), Relação amorosa, casamento, separação e terapia de casal (pp. 25-36). Rio de Janeiro: Anpepp. Bauman, Z. (2004). Amor líquido: sobre a fragilidade dos laços humanos. Rio de Janeiro: Zahar Ed. Bereisntein, I., \& Puget, J. (1993). Psicanálise do casal. Porto Alegre: Artes Médicas.

Chauí, M. (1982). Cultura e democracia. São Paulo: Moderna.

Dias, A. G. (2007). Campo-relação na clínica conjugal: reflexóes psicanalíticas sobre a cultura hoje. (Dissertação de Mestrado. Programa de Pós-Graduação em Psicologia. Universidade Federal de Uberlândia, Uberlândia, Minas Gerais).

Féres-Carneiro, T., \& Ziviani, C. (2009). Conjugalidades contemporâneas: um estudo sobre os múltiplos arranjos conjugais na atualidade. In T. Féres-Carneiro (Ed.), Casal e família: permanências e rupturas (pp. 83-107). São Paulo: Casa do Psicólogo.

Filho, O. (2009). A civilização do mal-estar pela não felicidade. Revista brasileira de psicanálise, 43(2), 183-192.

Fortes, I. (2007). Erotismo versus masoquismo na teoria freudiana. Psicologia clínica, 19(2), $35-44$.

Fortes, I. (2009). A psicanálise face ao hedonismo. Mal-estar e subjetividade, 9(4), 1123-1144. Freud, S. (1974). O problema econômico do masoquismo. In S. Freud, Obras psicológicas de Sigmund Freud (pp. 103-124). Edição standard de obras completas de Sigmund Freud, v. 19. Rio de Janeiro: Imago. (Trabalho original publicado em 1924)

Freud, S. (1980). Inibição, sintoma e ansiedade. In S. Freud, Obras psicológicas de Sigmund Freud (pp. 95-203). Edição standard de obras completas de Sigmund Freud, v. 20. Rio de Janeiro: Imago. (Trabalho original publicado em 1925)

Freud, S. (1980). O mal-estar na civilização. In S. Freud, Obras psicológicas de Sigmund Freud (pp. 81-178). Edição Standard de obras completas de Sigmund Freud, v. 21. Rio de Janeiro: Imago. (Trabalho original publicado em 1930)

Gomes, P. B., \& Porchat, I. (2006). Psicoterapia do casal. São Paulo: Casa do Psicólogo.

Hirigoyen, M.-F. (2006). A violência no casal: da coação psicológica à agressáa física. Rio de Janeiro: Bertrand Brasil.

Jablonski, B. (2007). O cotidiano do casamento contemporâneo: a difícil e conflitiva divisão de tarefas e responsabilidades entre homens e mulheres. In T. Féres-Carneiro (Ed.), Família e casal: saúde, trabalho e modo de vinculação (pp. 203-228). São Paulo: Casa do Psicólogo.

Lasch, C. (1998). A cultura do narcisismo. Rio de Janeiro: Imago.

Levy, L., \& Gomes, I. C. (2008). Relação conjugal, violência psicológica e complementaridade fusional. Psicologia clínica, 20(2), 163-172.

Lipovetsky, G. (1983). A era do vazio: ensaio sobre o individualismo contemporâneo. Lisboa: Gallimard. 
Lipovetsky, G. (2004). Os tempos hipermodernos. São Paulo: Barcarolla.

Marin, I. S. (2004). Sofrimento e violência na contemporaneidade: destinos subjetivos. In M. Khouri, J. Pastore, I. Sucar, R. Ajzenberg, \& R. Filho (Eds.), Leituras psicanaliticas da violência (pp. 85-100). São Paulo: Casa do Psicólogo.

Winnicott, W. (2000). Da pediatria à psicanálise. Rio de Janeiro: Imago. (Trabalho original publicado em 1956)

Zago, A. V. (2009). Mulheres que escolhem o presidiário como parceiro amoroso - uma formação de casal específica. In I. C. Gomes (Ed.). Clínica psicanalítica de casal e família. A interface com os estudos psicossociais (pp.109-119). São Paulo: Santos Editora.

Recebido em 29 de dezembro de 2011 Aceito para publicação em 10 de junho de 2012 